\title{
Fournier Gangrene in the Emergency Department: Diagnostic Dilemmas, Treatments and Current Perspectives
}

This article was published in the following Dove Press journal: Open Access Emergency Medicine

\author{
Jonathan Auerbach' \\ Kasha Bornstein' \\ Mark Ramzy $\mathbb{D D}^{2}$ \\ Jorge Cabrera' \\ Tim Montrief $\mathbb{D}^{2}$ \\ Brit Long ${ }^{3}$
}

'Department of Pulmonary, Allergy, Critical Care and Sleep Medicine, University of Miami Miller School of Medicine, Miami, FL, USA; ${ }^{2}$ Department of Critical Care Medicine, University of Pittsburgh Medical Center, Pittsburgh, PA, USA; ${ }^{3}$ Department of Emergency Medicine, Brooke Army Medical Center, San Antonio, TX, USA
Correspondence: Tim Montrief University of Pittsburgh, 3550 Terrace Street, 644A Scaife Hall, Pittsburgh, PA I526I, USA

Tel +I 5172605629

Fax +I 5I5 2034625

Email timothy.montrief@jhsmiami.org

\begin{abstract}
Fournier gangrene (FG) is a rare and life-threatening urosurgical emergency characterized most often by a polymicrobial infection of the perineal, genital, or perianal region. FG has an increased incidence in male patients, patients with alcoholism, and patients with immunocompromise including human immunodeficiency virus (HIV) and uncontrolled diabetes. FG often begins as a simple abscess or cellulitis with progression to necrotizing soft tissue infection (NSTI). Delays in diagnosis and treatment confer high mortality. Early recognition and high clinical suspicion are important in making a timely diagnosis, as early manifestations are often subtle. The most significant modifiable risk factor associated with NSTI mortality is delay to surgical intervention. Coordination of both inpatient medical and surgical teams to implement appropriate therapy is vital to successful outcomes. The emergency medicine clinician must be vigilant for this condition and be aware of risk factors, prognostic indicators, and proper treatment protocols to recognize FG early and initiate appropriate management. The objective of this review is to provide updated and relevant information regarding recognition, diagnosis, and management of FG for the emergency medicine provider.
\end{abstract}

Keywords: necrotizing soft tissue infections, infectious disease, necrotizing fasciitis, emergency

\section{Introduction}

Historical records of genital gangrene date back to Abu Ali al-Husayn ibn Sina (CE 980-1037), a Persian physician and a founder of early modern medicine. ${ }^{1}$ Ibn Sina described genital gangrene as an operative complication of the transperineal approach to renal calculus removal, noting the finding was an "alarm of patient death." "The first modern descriptions of regional perineal gangrene were reported by a Dr. H Baurienne, noting scrotal edema in a boy gored by an ox in 1764, and Robert Robertson, a British naval surgeon, in the publication of his 1772-1774 ship logs. ${ }^{1,2}$ Robertson described the case of the ship butcher, an elderly male "given to drinking" who, after a sexual encounter, developed penile and scrotal edema progressing to overwhelming infection and death within 72 hours of initial symptoms. $^{1,2}$ Although other physicians described genital gangrene, Fournier Gangrene (FG) was ultimately named for the French venereologist Jean Alfred Fournier (CE 1832-1914) who described it in a case series of patients in $1883 .{ }^{1}$ Fournier lectured and wrote about FG, which he had diagnosed in previously healthy men. The underlying etiology was unknown at the time, and it was thought 
to be an idiopathic disease of young men. ${ }^{3}$ Despite Fournier's name given to the eponym, earlier physicians more accurately described the infection as occurring following an initial traumatic insult, particularly in susceptible populations. A cause is now found in the majority of cases, and it can present at any age and any sex. ${ }^{4}$

FG is part of a group of infections described as necrotizing soft tissue infections (NSTIs). NSTIs are monomicrobial or synergistic polymicrobial infections involving any or multiple layers of the soft tissue, including cellulitis, fasciitis, and myositis. NSTIs are characterized by rapid tissue destruction and systemic signs of toxicity including features of sepsis and/or septic shock. ${ }^{5}$ Whereas sepsis mortality has declined globally in recent decades with improved recognition and treatment, retrospective studies evaluating FG outcomes have noted mortality has remained stable. ${ }^{6,7}$ Delays in diagnosis and treatment confer up to an $88 \%$ mortality. $^{7-9}$ The most significant modifiable risk factor for NSTI mortality is time to surgical intervention. ${ }^{10}$ Early intervention has the potential to decrease mortality by half. ${ }^{11}$

\section{Materials and Methods}

This narrative review provides a focused evaluation and management of FG in the emergency department (ED). The authors searched PubMed and Google Scholar for articles with the key words "necrotizing fasciitis" OR "necrotizing soft tissue infection" OR "Fournier gangrene" and "emergency". The search was conducted from database induction to January 1, 2020. PubMed yielded over 1022 articles. The first 400 articles in Google Scholar were also searched. Authors evaluated case reports and series, retrospective, and prospective studies, systematic reviews and meta-analyses, and other narrative reviews. Authors also reviewed guidelines and supporting citations of included articles. The literature search was restricted to studies published in English, with focus on emergency medicine and critical care literature. Authors decided which studies to include for the review by consensus. When available, systematic reviews and meta-analyses were preferentially selected. These were followed sequentially by randomized controlled trials, prospective studies, retrospective studies, case reports, and other narrative reviews when alternate data were not available. A total of 97 articles were selected for inclusion in this narrative review.

\section{Discussion}

Fournier gangrene is a life-threatening urosurgical emergency characterized by a polymicrobial infection of the perineal, genital, or perianal region that may rapidly progress to sepsis, septic shock, fulminant multi-organ dysfunction, and death. FG is rare (representing $<0.02 \%$ of all hospital admissions), and typically underdiagnosed prior to development of severe symptoms. ${ }^{12}$ The most recent largescale analysis of FG cases in the United States (US) noted the incidence of $\mathrm{FG}$ is approximately 1.6 per 100,000 males, which peaks between the ages of 50 and 79 years (3.3 per 100,000). The incidence of FG among female patients was reported as 0.25 per 100,000 in one study, though female patients were more acutely ill at presentation, required mechanical ventilation and dialysis twice as often, experienced longer length of stay, and had higher case fatality than the male cases. ${ }^{13}$ Differential severity by sex is reported in other databases as well. A study of FG in Japanese patients noted female patients were more likely to be older and experience higher case fatality. ${ }^{11}$ The US-South demonstrates the greatest burden of FG at 1.9 cases per $100,000 .^{9,13}$ Increasing population prevalence of diabetes is strongly associated with risk of $\mathrm{FG}$, with an increase of $0.2 \mathrm{FG}$ cases/100,000 males for each $1 \%$ increase in diabetes prevalence. ${ }^{13}$ Early signs of infection are subtle, and severe infection is associated with severe morbidity and mortality, even with appropriate therapy. Rapid recognition leading to timely diagnosis and treatment is essential to attenuate significant morbidity and mortality.

Between $26 \%$ and $30 \%$ of patients with FG may have no comorbidities, though there are numerous risk factors for development of infection (Table 1). ${ }^{9,14}$ Comorbid conditions including vascular disease or immunosuppression are highly associated with disease occurrence and mortality. Diabetes mellitus is present in $20-70 \%$ of FG cases, and $25-50 \%$ of patients have a history of chronic alcohol use. ${ }^{15}$ In regions with endemic HIV rates, HIV is the most common cited underlying risk factor. ${ }^{16}$ Risk of mortality is significantly heightened in patients with diabetes, heart disease, and renal failure. ${ }^{3}$ Additional risk factors include recent trauma or surgery and use of injection drugs such as cocaine or heroin, particularly if patients inject directly into inguinal veins, penile veins, or cavernosa. ${ }^{17,18}$ Use of sodium-glucose cotransporter 2 inhibitors (SGLT2i) antihyperglycemics that augment urinary glucose excretion - have been related with FG in multiple case reports, 
Table I Risk Factors for Development of Fournier Gangrene

\begin{tabular}{|c|c|}
\hline Demographic & $\begin{array}{l}\text { - Male sex } \\
\text { - Advanced age }(>50 \text { years) } \\
\text { - Spinal cord injury }{ }^{26} \\
\left.\text { - Obesity (BMl }>30 \mathrm{~kg} / \mathrm{m}^{2}\right) \\
\text { - Malnourishment } \\
\text { - Recent trauma or surgery } \\
\text { - Structural or functional anatomic } \\
\text { - Uefects } \\
\text { - Inguinal hernia }{ }^{28} \\
\text { - Rectal fistula } \\
\text { - Perianal abscess } \\
\text { - Lower extremity paralysis } \\
\text { - Neurogenic bladder }\end{array}$ \\
\hline Vascular Disease & $\begin{array}{l}\text { - Peripheral vascular disease } \\
\text { - Hypertension }\end{array}$ \\
\hline $\begin{array}{l}\text { Immunocompromised } \\
\text { State }\end{array}$ & $\begin{array}{l}\text { - Diabetes mellitus } \\
\text { - HIV/AIDS } \\
\text { - Chronic/high-dose steroid use } \\
\text { - Cytotoxic drugs including chemo } \\
\text { therapy } \\
\text { - Lymphoproliferative diseases } \\
\text { - Leukemia }{ }^{30} \\
\text { - Systemic lupus erythematosus } \\
\text { - Inflammatory bowel disease }{ }^{31} \\
\text { - Rectal/colon malignancy }\end{array}$ \\
\hline Drug Use & $\begin{array}{l}\text { - Alcohol use } \\
\text { - Tobacco use } \\
\text { - Stimulant use } \\
\text { - Injection drug use } \\
\text { - SGLT2 inhibitor use }{ }^{20}\end{array}$ \\
\hline $\begin{array}{l}\text { Chronic Organ } \\
\text { Dysfunction }\end{array}$ & $\begin{array}{l}\text { - Chronic kidney disease } \\
\text { - Hepatic insufficiency } \\
\text { - Heart failure }\end{array}$ \\
\hline latrogenic/Procedural & $\begin{array}{l}\text { Urologic } \\
\text { - Urinary catheterization or instru } \\
\text { mentation } \\
\text { - Prostatic biopsy } \\
\text { - Vasectomy } \\
\text { - Urethral stricture manipulation } \\
\text { Gastrointestinal } \\
\text { - Pancreatic stent dislocation } \\
\text { - Inguinal hernia repair } \\
\text { - Rectal biopsy } \\
\text { Gynecologic } \\
\text { - Episiotomy wound/repair } \\
\text { - Hysterectomy }\end{array}$ \\
\hline
\end{tabular}

Note: Data from these studies. ${ }^{9,15,20,22-25}$ resulting in a warning from the US Food and Drug Administration in 2018 for patients to seek attention if experiencing symptoms of genital discomfort, erythema, and fever while taking an SGLT2i. ${ }^{19}$ However, this link remains unclear as the risk of FG is already significantly higher in patients with diabetes, and large-scale analyses comparing SGLT2 $\mathrm{i}$ to other antihyperglycemics have found no increased risk of developing FG. ${ }^{19-21}$

\section{Etiology}

Fournier gangrene most often occurs in the setting of compromised host immunity, with introduction or seeding of mixed flora from an initial infectious foci into perineal tissue. ${ }^{14}$ The infection is typically polymicrobial, involving mixed aerobic and anaerobic bacteria of the gastrointestinal and genitourinary tracts as well as cutaneous microorganisms. ${ }^{15,33-35}$ Approximately one-quarter of FG cases are idiopathic with no known source. ${ }^{3}$ However, the pathological processes leading to perineal and genital gangrene and sepsis can usually be tracked back to a gastrointestinal, genitourinary, or cutaneous primary lesion.

\section{Anatomical Considerations}

Knowledge of perineal fascial anatomy is critical for understanding the natural history and course of FG. Beginning from initial foci of infection in the abdomen, genitalia, or perineum, FG advances along fascial planes, facilitating rapid extension of infection and necrosis deep into contiguous tissues and ultimately involving pelvic organs. ${ }^{33}$ Due to the nature of spread, deep infections can present with few superficial cutaneous findings. When present, exact anatomical location of skin findings may indicate the course and extent of infection spread and may help to determine the original foci of infection if unclear or unavailable from the history. ${ }^{15}$

Infections originating in the perineum or rectum most often involve tissues of the scrotum, penis, and anterior abdominal wall, as far cephalad as the clavicles. ${ }^{15,36}$ Deeper muscular structures of the pelvis and deep penile tissues including the corpora cavernosa, urethra, and spermatic cord structures are not typically involved unless they are the original source of infection. ${ }^{15}$ As the testicular blood supply of these structures derives directly from the abdominal aorta before bifurcation into the iliac arteries, 
involvement of the testes suggests that the infection either originated from or has expanded into the retroperitoneal space. Anorectal sources of infection, such as may occur in the setting of rectal fistula, prostate biopsy, or colonoscopy, will usually begin perianally and spread outwards. Urogenital infections initially involve the superficial (Colles) fascia and deep fascia of the genitalia. ${ }^{24}$ The continuous nature of Colles fascia with Buck's and Dartos fascial planes allows for caudal spread of infection, though spread to involve the anal margin is typically limited by anatomic attachment of Colles fascia at the perineal body. ${ }^{24}$

\section{Microbiology}

Necrotizing soft tissue infections, including FG, may be broadly categorized into four types based on the underlying pathogenic organism driving the infectious process. Type I NSTIs are the most common and are characterized by polymicrobial flora including both gram-positive and gramnegative organisms, anaerobes, and/or clostridial species. Type II NSTIs are typified by monomicrobial involvement, involving $\beta$-hemolytic Group A Streptococcus (GAS) species or Staphylococcus aureus. Type III NSTIs involve monomicrobial gram-negative marine-related infections such as Vibrio vulnificus, Aeromonas hydrophila, or clostridium species. Type IV NSTI infections involve fungal organisms and are most common in patients with severe immunosuppression and traumatic wounds including burns. ${ }^{37,38}$

Fournier gangrene is most often characterized as a Type I NSTI, with up to $80 \%$ of FG involving several different microbes. ${ }^{33}$ Upwards of four discrete organisms may be found in blood cultures in affected patients. ${ }^{33,39}$ Commonly isolated organisms represent normal commensal flora of the anatomic region below the pelvic diaphragm including the perineum, rectum, and vagina. ${ }^{15}$ In the setting of impaired host immunity, these organisms behave synergistically, with aerobes and anaerobes producing exotoxins and enzymes that destroy tissue and extend infection. ${ }^{15}$ Bacteroides impair phagocytosis of aerobic bacteria, which induce platelet aggregation and complement fixation, while anaerobe-produced heparinase encourages coagulation and thrombosis of local microvasculature. ${ }^{24}$ Critical ischemia and tissue invasion by commensal organisms in the area then progress to gangrene. ${ }^{40}$ Aerobic microorganisms cultured from wounds and blood samples include Escherichia coli, Klebsiella pneumoniae, and S. aureus. Anaerobic microorganisms include Bacteroides fragilis and Clostridium species. $^{8,33}$ Other species isolated include Streptococcus, Vibrio, Enterococcus, Pseudomonas,
Proteus, and Corynebacterium. ${ }^{12,22}$ Case reports of antibiotic-resistant bacterial strains, such as methicillin-resistant $S$. aureus (MRSA), as well as extended-spectrum beta lactamase (ESBL) resistant Escherichia coli have been reported with increasing incidence in immunosuppressed patients. ${ }^{41}$

Type II FG most often involves Streptococcus pyogenes, though other GAS strains including $S$. dysgalactiae have been reported. ${ }^{42} \beta$-hemolytic streptococcal NSTI are complicated by streptococcal toxic shock syndrome in over $50 \%$ of cases, involving T-cell activation and generalized release of pro-inflammatory cytokines leading to capillary leak and arterial hypotension. ${ }^{43}$ Hypoperfusion further impairs local host defenses, exacerbates microcirculatory thrombosis of vascular supply to fascia, and accelerates necrosis of fascial structures. ${ }^{44}$

Type III FG most commonly involves $C$. perfringens or A. hydrophila. $^{45}$ There are no reported cases of $V$. vulnificus-associated FG. C. perfringens is most associated with recent traumatic injury. ${ }^{45}$

Type IV FG has been described in immunologically vulnerable patients including infants, patients with cancer, and patients with therapeutic immunosuppression for autoimmune disease. ${ }^{46}$ While Candida species are part of the commensal flora of the gastrointestinal and genitourinary tracts, they can cause acute disease in the context of compromised host immunity. The most common fungal organism reported in Type IV FG is Candida albicans, though other Candida species are also rarely implicated as a cause of FG. Cases associated with Candida glabrata, Lactobacillus gasseri, Rhizopus microspores, and Zygomycetes are described in the literature. ${ }^{27,47-52}$

\section{History and Physical Examination}

FG is a clinical diagnosis. There are no specific laboratory or imaging studies that can specifically rule in or out the disease. Early-stage FG is a difficult diagnosis to make and is misdiagnosed in up to three quarters of cases, contributing to higher mortality as the infection progresses. ${ }^{53,54}$ Although FG is most often thought of as an acute process, patient presentations range from days to weeks. Indolent and smoldering infections can develop over the course of several weeks, to subacute infections occurring over days to weeks, to fulminant infections with rapid progression to shock and multiorgan failure. ${ }^{55,56}$ One study found the mean interval between initial symptom onset and hospital arrival was $5.1 \pm 3.1$ days. ${ }^{56}$ Talwar et al describe a typical natural history involving the following: ${ }^{57}$ 
(a) Prodromal symptoms of fever and lethargy, which may be present for two to seven days.

(b) Intense genital pain and tenderness that is usually associated with edema of the overlying skin.

(c) Increasing genital pain and tenderness with progressive erythema of the overlying skin.

(d) Dusky appearance of the overlying skin; subcutaneous crepitation.

(e) Obvious gangrene of a portion of the genitalia; purulent drainage from the wounds.

Close investigation and a high index of suspicion is necessary when examining the perineum and genitalia in all patients. However, exceptional attention should be directed towards thorough examination in obese patients, elderly patients, patients with dementia, obtunded patients, patients with lower extremity paralysis, and non-verbal patients as these areas may be infrequently checked. ${ }^{26,58}$ All but the most severe NSTIs typically present subtly in the initial stages of infection, confounding the most critical modifiable risk factor for NSTI mortality; time to surgical intervention.

Earliest signs of FG include local tenderness, pruritus, edema, and erythema of the scrotal or labial skin (Figure 1). These examination findings mimic milder soft tissue infections such as cellulitis, impetigo, and erysipelas, though these infections typically have clearly demarcated borders versus the patchy erythema and erratic bulla formation of FG. ${ }^{12,59}$ Abrasions and fluctuance of the genitalia and perineum should raise suspicion for FG. ${ }^{17}$ Skin changes including crepitation upon palpation of affected tissues, bronzing, purpura, bulla formation, and patchy anthracosis indicate disease progression. ${ }^{53}$ Presence of crepitus and subcutaneous gas is highly specific for gas-forming organisms, most often clostridial infections. ${ }^{5}$ Exquisite tenderness or pain out of proportion to examination is a cardinal finding. As infection spreads

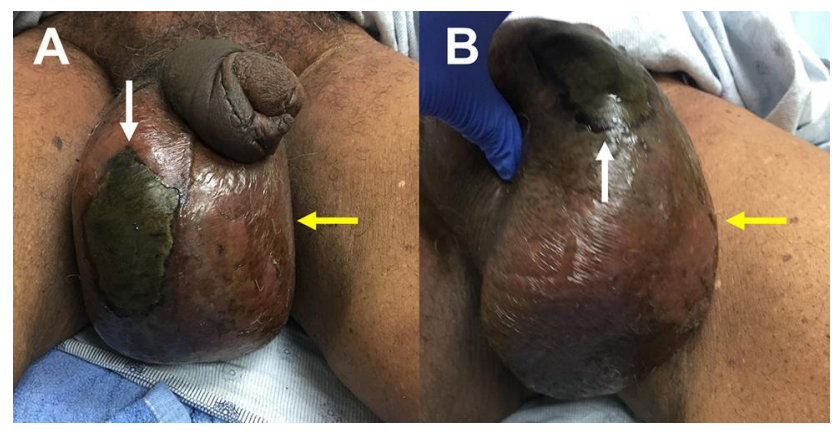

Figure I Physical examination findings of Fournier Gangrene. Note a large area of necrosis (white arrow) as well as soft tissue edema and erythema (yellow arrow). rapidly along fascial planes, tenderness and erythema may extend beyond the apparent area of involvement, up the anterior abdominal and into the proximal lower extremities. ${ }^{60}$ Affected areas may appear dusky or swollen and have the classic presentation of feculent, musty, or "sweetly putrid" odor, and "dishwater" purulent discharge due to anaerobic infection (Figure 1). ${ }^{56,61,62}$ Dishwater discharge is thin, purulent seepage specific for Clostridium perfringens gas gangrene and results from clostridial toxin-induced neutrophil lysis. Hypotension, shock, and organ dysfunction are late findings in these patients, and associated with high morbidity and mortality. ${ }^{53,63}$

\section{Laboratory Investigations and Clinical Scoring Systems}

There are no specific laboratory tests or biomarkers for NSTI or FG. No single laboratory test has adequate sensitivity and specificity to discern FG, or any NSTI, from other soft tissue infections. Laboratory data may be used in aggregate to prognosticate illness and predict mortality.

Given the high mortality and rapid progression to moribund status, multiple risk calculators have been developed to facilitate early evaluation of disease severity. Each of these risk calculators utilize laboratory data to produce clinical scores associated with overall prognosis, as well as predicting necessity of specific interventions. These tools include the Fourniers Gangrene Severity Index (FGSI), Uludag Fournier Gangrene Severity Index (UFGSI), Age-Adjusted Charlson Comorbidity Index (ACCI), the Laboratory Risk Indicator for Necrotizing Fasciitis (LRINEC) score, the Combined Urology and Plastics Index (CUPI) and the Platelet Mass Index (PMI) Score. ${ }^{63-65}$

The LRINEC score aggregates data including C-reactive protein, extent of leukocytosis, hemoglobin, serum sodium, serum creatinine, and glucose to suggest presence of NSTI (Table 2). The score explicitly cannot exclude NSTI. Score ranges from 0 to 13 with composite scores $\geq 6$ concerning for NSTI. ${ }^{66}$ A significant drawback of the LRINEC scoring system is its poor sensitivity among ED patients. ${ }^{67}$ One large study of the LRINEC score performance in the emergency setting found sensitivity for FG ranging between $68 \%$ and $80 \%$, unacceptably low given the marked mortality associated with delay to definitive surgical management. ${ }^{63,66-69}$ There have also been cases of NSTI with LRINEC scores of zero. ${ }^{70}$ Due to the limited sensitivity of the LRINEC, it should not determine clinical decisionmaking for FG diagnosis, particularly in the ED setting. 
Table 2 LRINEC Score for Necrotizing Soft Tissue Infection

\begin{tabular}{|c|c|c|c|c|c|}
\hline Criteria & Value & Points & Criteria & Value & Points \\
\hline CRP (mg/L) & $\begin{array}{l}<150 \\
\geq 150\end{array}$ & $\begin{array}{l}0 \\
+4\end{array}$ & Sodium & $\begin{array}{l}\geq 135 \\
<135\end{array}$ & $\begin{array}{l}0 \\
+2\end{array}$ \\
\hline WBC per $\mathrm{mm}^{3}$ & $\begin{array}{l}<15 \\
15-25 \\
>25\end{array}$ & $\begin{array}{l}0 \\
+1 \\
+2\end{array}$ & Hemoglobin $(\mathrm{g} / \mathrm{dL})$ & $\begin{array}{l}>13.5 \\
11-13.5 \\
<11\end{array}$ & $\begin{array}{l}0 \\
+1 \\
+2\end{array}$ \\
\hline Creatinine & $\begin{array}{l}\leq 1.6 \mathrm{mg} / \mathrm{dL} \\
>1.6 \mathrm{mg} / \mathrm{dL}\end{array}$ & $\begin{array}{l}0 \\
+2\end{array}$ & Glucose & $\begin{array}{l}\leq 180 \mathrm{mg} / \mathrm{dL} \\
>180 \mathrm{mg} / \mathrm{dL}\end{array}$ & $\begin{array}{l}0 \\
+1\end{array}$ \\
\hline
\end{tabular}

Total LRINEC Score: $\mathbf{0}-13$

Note: Adapted from Hsiao CT, Chang CP, Huang TY, Chen YC, Fann WC, Spratley J. Prospective validation of the Laboratory Risk Indicator for Necrotizing Fasciitis (LRINEC) score for necrotizing fasciitis of the extremities. PLoS One. 2020;15(I):e0227748. Creative commons license and disclaimer available from: (http://creativecom $\underline{\text { mons.Org/licenses/by/4.0/legalcode) }}{ }^{71}$

The FGSI determines the severity and prognosis for patients with FG based on nine clinical parameters, scored from 0 to 4 . Components include body temperature; heart rate; respiratory rate; basic metabolic panel markers such as serum sodium, serum potassium, serum bicarbonate, and calculated creatinine, as well as blood cell parameters including hematocrit and leukocyte count (Table 3). ${ }^{72}$ A score of $>10.5$ is associated with a $96 \%$ probability of death and a score of $\leq 10.5$ a $96 \%$ probability of survival. ${ }^{72}$ Comparison of FGSI and LRINEC found similar strength in demonstrating worse prognosis including mechanical ventilation requirement and mortality. ${ }^{73}$
The neutrophil-lymphocyte ratio (NLR), plateletlymphocyte ratio (PLR), and monocyte-lymphocyte ratio (MLR) are newer validated clinical scoring tools with wide use for predicting disease severity in many inflammatory and infectious conditions, recently utilized for FG as well. ${ }^{74,75}$ Yim et al (2016) determined that admission labs demonstrating PLR> 140 and NLR $>8$ were associated with 11.6 and 4.66fold increased odds of mortality, respectively. ${ }^{75}$ Higher neutrophil-lymphocyte and platelet-lymphocyte ratios are indicative of worse prognosis. Retrospective comparison of the FGSI against NLR and PLR in patients with FG found higher NLR and PLR values correlated with higher mortality, including in

Table 3 FGSI Score and Performance

\begin{tabular}{|c|c|c|c|c|c|}
\hline Temperature $\left({ }^{\circ} \mathrm{C}\right)$ & Score & Serum Sodium (mmol/L) & Score & Serum Potassium (mmol/L) & Score \\
\hline$>41$ & 4 & $<110$ or $>180$ & 4 & $<2.5$ or $>7$ & 4 \\
\hline $30-31.9$ or $39-40.9$ & 3 & $111-119$ or $160-179$ & 3 & $6-6.9$ & 3 \\
\hline $32-33.9$ & 2 & $120-129$ or $155-159$ & 2 & $2.5-2.9$ & 2 \\
\hline $34-35.9$ or $38.5-38.9$ & I & $150-154$ & I & $3-3.4$ or $5.5-5.9$ & I \\
\hline $36-38.4$ & 0 & $130-149$ & 0 & $3.5-5.4$ & 0 \\
\hline Heart Rate (beats/min) & Score & Hematocrit (\%) & Score & Serum WBC (total $\left./ \mathrm{mm}^{3} \times 1000\right)$ & Score \\
\hline$<39$ or $>180$ & 4 & $<20$ or $>60$ & 4 & $<1$ or $>40$ & 4 \\
\hline $40-54$ or $140-179$ & 3 & $20-29.9$ or $50-59.9$ & 2 & $1-2.9$ or $20-39.9$ & 2 \\
\hline $55-69$ or $110-139$ & 2 & $46-49.9$ & I & $15-19.9$ & I \\
\hline $70-109$ & 0 & $30-45.9$ & 0 & $3-14.9$ & 0 \\
\hline Bicarbonate (mmol/L) & Score & Respiratory Rate (breaths/min) & Score & Test Characteristics & \\
\hline$<15$ or $>52$ & 4 & $<5$ or $>50$ & 4 & FGSI Score & $>9$ \\
\hline $15-17.9$ or $4|-5| .9$ & 3 & $35-49$ & 3 & Sensitivity & $67 \%$ \\
\hline $18-21.9$ & 2 & $6-9$ & 2 & Specificity & $96 \%$ \\
\hline $32-40.9$ & 1 & $10-11$ or $25-34$ & I & Positive LR & 16 \\
\hline $22-31.9$ & 0 & $12-24$ & 0 & Negative LR & 0.4 \\
\hline
\end{tabular}

Note: Adapted by permission from Springer Nature, Int Urol Nephrol. Kabay S, Yucel M, Yaylak F, et al. The clinical features of Fournier's gangrene and the predictivity of the Fournier's gangrene severity index on the outcomes. 40(4):997-1004, copyright (2008). ${ }^{72}$

Abbreviations: WBC, white blood cell; LR, likelihood ratio. 
patients for which the FGSI did not show any statistically significant effect on mortality. ${ }^{34,75,76}$ Additional benefits of the NLR and PLR tools are their simplicity of use and low cost, particularly in low resource settings. FGSI and NLR have also been used by urological services as reliable parameters for predicting skin reconstruction method between primary skin closure versus graft and flap. ${ }^{77}$ MLR has been used to predict necessity of repeat surgical debridement in FG, with higher MLR indicative of more debridement in a retrospective study. ${ }^{78}$ The PMI is calculated by multiplying the platelet count by the mean platelet volume. Based on limited scientific data, it may have better sensitivity and specificity than the LRINEC score with values of $\leq 2076.89$ portending a worse outcome. If high suspicion for necrotizing fasciitis is present based on clinical history and physical examination, early involvement of surgical services and progression to operative management takes precedence over any clinical scoring system.

\section{Imaging}

Although imaging can assist with the diagnosis, NSTIs including FG are a clinical diagnosis using meticulous history, fastidious physical examination, and a high index of suspicion. Ultimately the only definitive diagnosis is in the operating room. Hemodynamically unstable patients may require direct disposition to the operating room for definitive management if clinical suspicion is warranted, prior to imaging studies. It is important to note that imaging will not rule out this diagnosis and should not delay surgical intervention. ${ }^{24}$

Conventional radiography can be used to detect the presence of tissue edema and soft tissue emphysema along the fascial planes (Figure 2). This can be found earlier than crepitus on physical examination. $7,8,46$ Presence of gas is highly specific (94\%) for NSTI but bears poor sensitivity $(49 \%){ }^{45,63,79,80}$ While evidence of subcutaneous gas tracking along fascial planes is present in nearly half of all patients with FG, deep fascial gas may not be detected, resulting in false-negative radiographic studies. ${ }^{81}$ Conventional radiography is often used to rule out NSTI on the basis of absent soft tissue emphysema. However, emphysema is most specific to clostridial infection, which may not be present in non-clostridial polymicrobial Type I, monomicrobial Type II, or fungal Type IV NSTI. Over-reliance on radiographic tissue emphysema may distract clinicians from the correct diagnosis.

Computed tomography (CT) imaging can assist with diagnosis and planning for surgical management. CT has

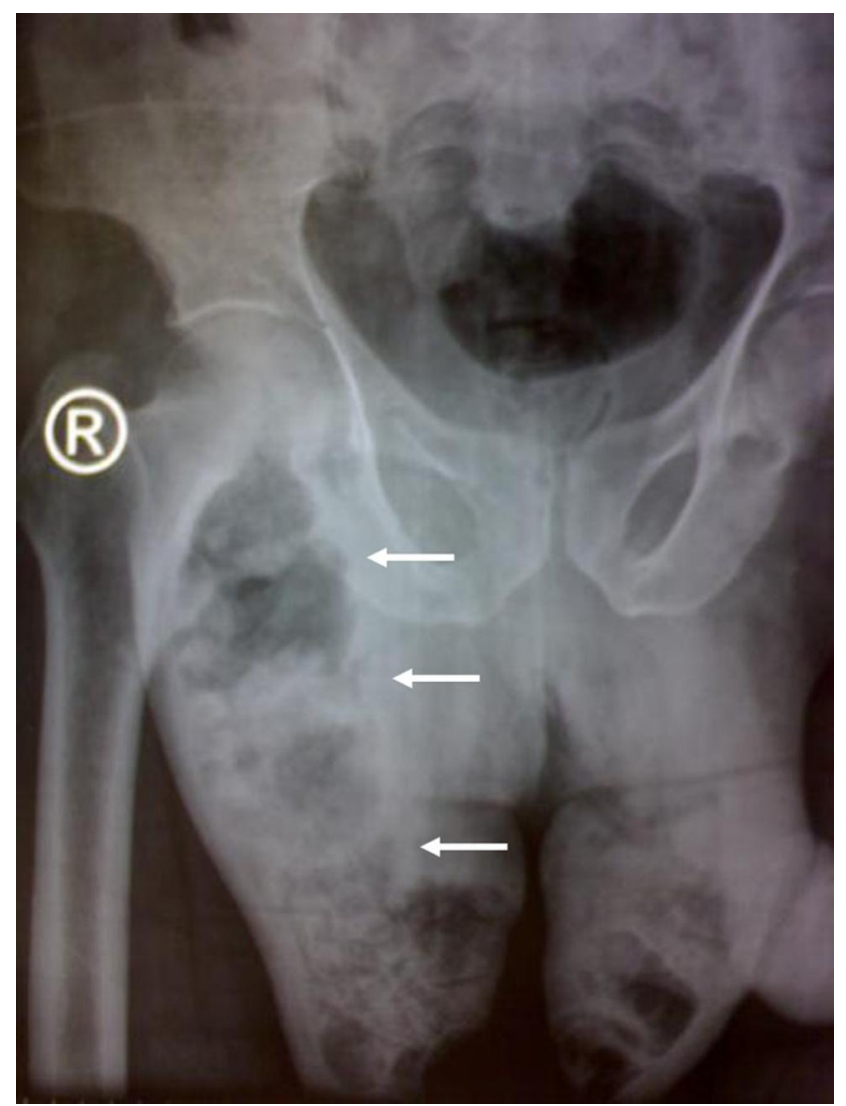

Figure 2 Anterior-Posterior Radiography of the Pelvis. Note the diffuse scrotal swelling with extensive soft tissue gas formation (white arrows) tracking along the right groin (R). Case courtesy of $\mathrm{Dr}$ Ahmed Abdrabou. Fournier gangrene. Radiopedia.org; rID:30310. Available from: https://radiopaedia.org/cases/fournier-gangrene-5?lang=us. ${ }^{98}$

high sensitivity (88.5\%) and specificity (93.3) for NSTI diagnosis. $3,7,63$ Common findings include fluid collections, abscesses, asymmetric fascial thickening, fat stranding, and subcutaneous emphysema (Figure 3). ${ }^{82-84}$ Although excellent at characterizing soft tissue, magnetic resonance imaging is not recommended as the initial radiologic imaging modality due to high cost and extended time of examination. ${ }^{5}$

Point of care ultrasound (POCUS) is a useful diagnostic aid in NSTI. Castleberg et al defined an imaging protocol using bedside ultrasound evaluating for subcutaneous thickening, air, and fascial fluid (STAFF), noting that presence of findings has high sensitivity (88\%) and specificity (93\%) for NSTI. ${ }^{60,85}$ Presence of intrascrotal gas is a pathognomonic sign of NSTI. $^{86}$ Additional characteristic findings on ultrasound include "cobblestoning" of the subcutaneous soft tissue (thin lines of fluid between globules of fat). Additional findings of subcutaneous gas include "snow globe" (heterogenous swirling matter) and "dirty shadowing" (when gas causes shadowing with a hazy appearance) appearance caused by hyperechoic foci demonstrating reverberation artifacts (Figure 4). ${ }^{82,86}$ 


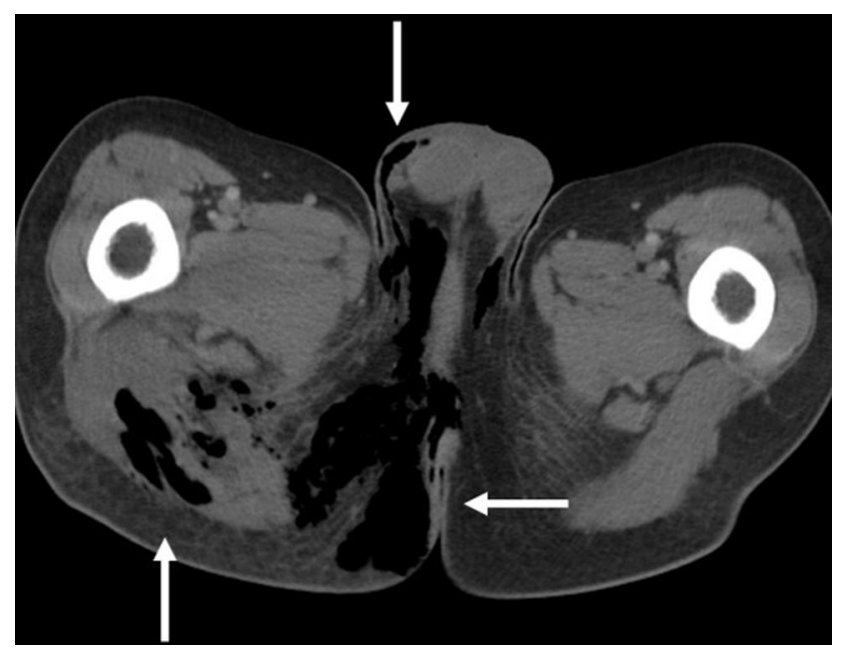

Figure 3 Sagittal Computed Tomography (CT) Image of the Perineum. Note the subcutaneous and fascial emphysema tracking from the rectum throughout the perineum and scrotum (white arrows). Case courtesy of Dr Chris O'Donnell. Fournier gangrene - spontaneous perforation of rectal cancer. Radiopedia.org; rID: 16849 . Available from: https://radiopaedia.org/cases/fournier-gangrene-sponta neous-perforation-of-rectal-cancer?lang=us. ${ }^{99}$

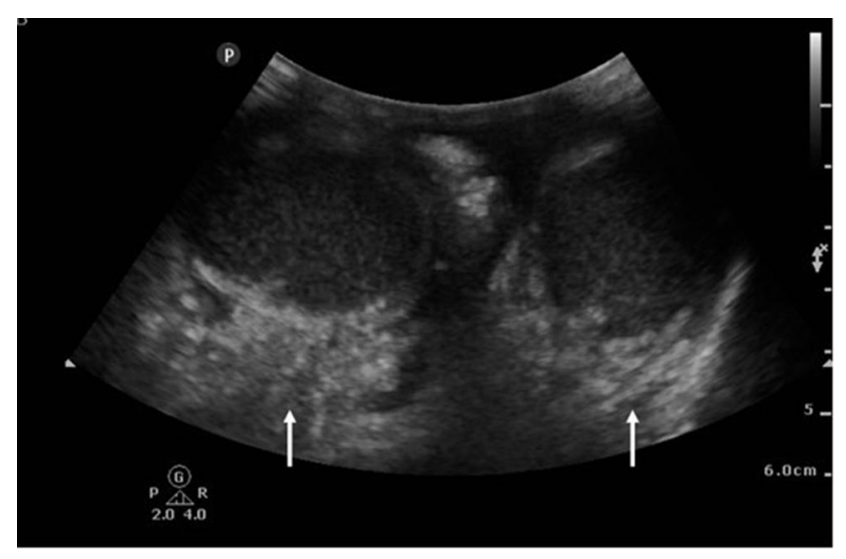

Figure 4 Point of care ultrasound image of the scrotum. Note the diffuse subcutaneous edema and subcutaneous gas adjacent to the testicles (white arrows). Case courtesy of Praveen Jha. Fournier gangrene. Radiopedia.org. rID: 18695. Available from: https://radiopaedia.org/cases/fournier-gangrene-I?lang=us. ${ }^{100}$

Additionally, POCUS application in suspected FG can differentiate between NSTI findings from other urogenital diseases that may result in scrotal pain, erythema, and swelling. ${ }^{86}$

\section{Management}

Emergent surgical debridement, broad spectrum antibiotics, and appropriate resuscitation with intravenous fluids and vasopressor medications are the cornerstones of FG therapy. ${ }^{5}$ As most FG cases are polymicrobial, appropriate antibiotic regimen should cover streptococcal, staphylococcal, and gram-negative bacteria; coliforms; Pseudomonas; Bacteroides; and Clostridium. ${ }^{5}$ Recommended therapy
Box I Empiric Antibiotic Regimen for Fournier's Gangrene

Carbapenem (Imipenem, meropenem, or ertapenem)

OR

Beta lactam-beta lactamase inhibitor (piperacillin-tazobactam or ampicillin-sulbactam)

PLUS

Clindamycin for its activity against gram-positive organisms and anaerobes, as well as its antitoxin effects

PLUS

Vancomycin, daptomycin, or linezolid for activity against gram-positive organisms and MRSA

In patients with severe hypersensitivity to carbapenems or beta lactam-beta lactamase inhibitors, consider:

Aminoglycoside

OR

Fluoroquinolone

PLUS

Metronidazole

In patients with salt or freshwater exposure, consider adding: Doxycycline

In patients with significant risk for fungal involvement, consider adding:

Amphotericin B or fluoroconazoles

Note: Reprinted from J Emerg Med. 57(4): Montrief T, Long B, Koyfman A, Auerbach J. Fournier gangrene: a review for emergency clinicians. 488-500, Copyright (2019), with permission from Elsevier. ${ }^{59}$

Abbreviation: MRSA, methicillin-resistant Staphylococcus aureus.

includes MRSA coverage (vancomycin or linezolid) with a carbapenem or beta lactamase inhibitor (Box 1). ${ }^{86}$ It is reasonable to add clindamycin, as there is some literature that this suppresses toxin production and mediates cytokine production in NSTI patients leading to decreased mortality. ${ }^{16,87}$ Doxycycline should be added in patients who have risk factors for $A$. hydrophila (ie, aquatic exposure). ${ }^{86} \mathrm{In}$ patients with clinical suspicion for fungal source of infection, Amphotericin B or fluconazole antifungals should be included in the antibiotic regimen. ${ }^{86}$

\section{Resuscitation}

Comorbidities considered the presence of septic shock with evidence of hypoperfusion may warrant administration of $30 \mathrm{~mL} / \mathrm{kg}$ of crystalloid fluid within the first 3 hours for patients with sepsis or septic shock and evidence of hypoperfusion. ${ }^{88}$ These should preferably be a balanced crystalloid such as Lactated Ringer's. ${ }^{90,91}$ Further fluid administration should be guided by hemodynamic parameters (heart rate, blood pressure, urine output, and lactate clearance) to gauge responsiveness to initial fluid resuscitation. ${ }^{89,91-94}$ Vasopressors may be used to support 
end-organ perfusion in patients with continued hypoperfusion after fluid optimization, with a preference towards early initiation of norepinephrine. ${ }^{91}$

\section{Surgical Intervention}

Prompt surgical consultation and intervention are crucial in these patients as the only definitive care is early, aggressive, and often repeat debridement. Delays in surgical consultation due to laboratory or imaging investigations negatively impact morbidity and mortality. ${ }^{10}$ An additional modifiable risk factor includes surgical familiarity with the disease; early consultation with the appropriate surgical team including urology, general surgery, acute care surgery, and/or obstetrics and gynecology can greatly benefit ultimate patient outcomes. ${ }^{10}$

\section{Hyperbaric Oxygen Therapy (HBOT)}

HBOT therapy can be considered as adjuvant therapy for its bactericidal and bacteriostatic effects, particularly in postsurgical patients. ${ }^{95,96}$ HBOT therapy should not be a consideration in the acute care setting as the most important intervention is prompt surgical management. Extremely ill postoperative patients may be poor candidates, as HBOT therapy limits access to perform critical life-saving interventions on these patients. Consideration for transfer to a center with HBOT availability should be made with discussion between surgical specialties at the referring and receiving centers.

\section{Intravenous Immunoglobulins and Therapeutic Plasma Exchange}

There are limited data supporting the use of intravenous immunoglobulins (IVIG). There is a theoretical benefit of neutralizing streptococcal toxins in NSTI associated with toxic shock syndrome; however, this has not been shown as of yet to be beneficial in the literature. ${ }^{89,97}$ Therapeutic plasma exchange (TPE) has been considered and is thought to remove inflammatory mediators. ${ }^{89}$ The current literature is not yet mature enough to make a recommendation at this time.

\section{Disposition}

Prompt surgical consultation and intervention with early surgical intensive care involvement allow for more timely management and handoff of the patients with NSTI's and are associated with decreased mortality. ${ }^{10,54}$ Typically patients with NSTI will require intensive care management. Transfer of NSTI patients is reasonable for resourcelimited facilities and should occur in consultation with surgical teams at the transferring and receiving facilities. ${ }^{97}$

\section{Future Research Considerations}

Future research considerations should include external validation of NLR, MLR and PLR; more accurate scoring systems with higher sensitivity and specificity; and more robust studies on the role of complementary interventions including IVIG and TPE in FG.

\section{Conclusion}

Emergency clinicians must be vigilant about FG diagnosis, as delay augments high mortality and morbidity rates. ${ }^{7}$ FG is a clinical diagnosis with no laboratory or imaging results that can reliably exclude this condition. Therefore, high clinical suspicion must be maintained for altered, elderly, patients with pain out of proportion to examination, rapidly spreading infection, ecchymosis, crepitus, and bullae of the genital area. Although no scoring system has a high enough sensitivity and specificity to rule in or out FG, scoring systems such as the LRINEC or FGSI scores may assist with diagnostic dilemmas. Newer prognostic markers including NLR, PLR and PMI may offer faster risk stratification and efficient surgical disposition. Definitive diagnosis and treatment include aggressive operative management, appropriate early resuscitation, broadspectrum antibiotics, and timely surgical consultation. Further study is needed regarding the roles of IVIG and plasma exchange.

\section{Disclosure}

The authors report no conflicts of interest in this work.

\section{References}

1. Short B. Fournier gangrene: an historical reappraisal. Intern Med J. 2018;48(9):1157-1160. doi:10.1111/imj.14031

2. Grzybowski A, Short A. History of Fournier gangrene. Arch Dermatol. 2009;145(2):182. doi:10.1001/archdermatol.2008.595

3. El-Qushayri AE, Khalaf KM, Dahy A, et al. Fournier's gangrene mortality: a 17-year systematic review and meta-analysis. Int $J$ Infect Dis. 2020;92:218-225. doi:10.1016/j.ijid.2019.12.030

4. Filippone LM. MD diagnosis: Fournier's gangrene. Emerg Med News. 2005;27(5):36. doi:10.1097/00132981-200505000-00029

5. Hakkarainen TW, Kopari NM, Pham TN, Evans HL. Necrotizing soft tissue infections: review and current concepts in treatment, systems of care, and outcomes. Curr Probl Surg. 2014;51(8):344-362. doi:10.1067/j.cpsurg.2014.06.001

6. Rudd KE, Johnson SC, Agesa KM, et al. Global, regional, and national sepsis incidence and mortality, 1990-2017: analysis for the Global Burden of Disease Study. Lancet. 2020;395(10219):200-211. doi:10.1016/S0140-6736(19)32989-7

7. Radcliffe RS, Khan MA. Mortality associated with Fournier's gangrene remains unchanged over 25 years. BJU Int. 2020;125(4):610-616. doi:10.1111/bju.14998

8. Bjurlin MA, O'Grady T, Kim DY, et al. Causative pathogens, antibiotic sensitivity, resistance patterns, and severity in a contemporary series of Fournier's gangrene. Urology. 2013;81(4):752-758. doi:10.1016/j.urology.2012.12.041 
9. Sorensen MD, Krieger JN, Rivara FP, et al. Fournier's Gangrene: population based epidemiology and outcomes. J Urol. 2009;181 (5):2120-2126. doi:10.1016/j.juro.2009.01.034

10. Peetermans M, de Prost N, Eckmann C, Norrby-Teglund A, Skrede S, De Waele JJ. Necrotizing skin and soft-tissue infections in the intensive care unit. Clin Microbiol Infect. 2020;26(1):8-17. doi:10.1016/j.cmi.2019.06.031

11. Sugihara $\mathrm{T}$, Yasunaga $\mathrm{H}$, Horiguchi $\mathrm{H}$, et al. Impact of surgical intervention timing on the case fatality rate for Fournier's gangrene: an analysis of 379 cases. BJU Int. 2012;110(11c):E10961100. doi:10.1111/j.1464-410X.2012.11291.x

12. Voelzke BB, Hagedorn JC. Presentation and diagnosis of Fournier gangrene. Urology. 2018;114:8-13. doi:10.1016/j.urology.2017.10.031

13. Sorensen MD, Krieger JN. Fournier's gangrene: epidemiology and outcomes in the general US population. Urol Int. 2016;97 (3):249-259. doi:10.1159/000445695

14. Mishra SP, Singh S, Gupta SK. Necrotizing soft tissue infections: surgeon's prospective. Int $J$ Inflam. 2013;2013:609628. doi:10.1155/2013/609628

15. Thwaini A, Khan A, Malik A, et al. Fournier's gangrene and its emergency management. Postgrad Med J. 2006;82 (970):516-519. doi:10.1136/pgmj.2005.042069

16. Elem B, Ranjan P. Impact of immunodeficiency virus (HIV) on Fournier's gangrene: observations in Zambia. Ann R Coll Surg Engl. 1995;77(4):283-286.

17. Moussa M, Abou Chakra M. Isolated penile Fournier's gangrene: a case report and literature review. Int J Surg Case Rep. 2019;62:65-68. doi:10.1016/j.jiscr.2019.08.012

18. Mouraviev VB, Pautler SE, Hayman WP. Fournier's gangrene following penile self-injection with cocaine. Scand $J$ Urol Nephrol. 2002;36(4):317-318. doi:10.1080/ 003655902320248326

19. Bloomgarden Z, Einhorn D, Grunberger G, Handelsman Y. Fournier's gangrene and sodium-glucose cotransporter 2 inhibitors: is there a causal association? J Diabetes. 2019;11 (5):340-341. doi:10.1111/1753-0407.12897

20. Yang JY, Wang T, Pate V, Buse JB, Stürmer T. Real-world evidence on sodium-glucose cotransporter-2 inhibitor use and risk of Fournier's gangrene. BMJ Open Diabetes Res Care. 2020;8(1):e000985. doi:10.1136/bmjdrc-2019-000985

21. Dass AS, Immaculate G, Bhattacharyya A. Fournier's gangrene and sodium-glucose co-transporter 2(SGLT2) inhibitors: our experience. Indian J Endocrinol Metab. 2019;23(1):165-166. doi:10.4103/ijem. IJEM 61418

22. Aridogan IA, Izol V, Abat D, Karsli O, Bayazit Y, Satar N. Epidemiological characteristics of Fournier's gangrene: a report of 71 patients. Urol Int. 2012;89(4):457-461. doi:10.1159/ 000342407

23. Martinschek A, Evers B, Lampl L, Gerngroß H, Schmidt R, Sparwasser C. Prognostic aspects, survival rate, and predisposing risk factors in patients with Fournier's gangrene and necrotizing soft tissue infections: evaluation of clinical outcome of 55 patients. Urol Int. 2012;89(2):173-179. doi:10.1159/000339161

24. Chennamsetty A, Khourdaji I, Burks F, Killinger KA. Contemporary diagnosis and management of Fournier's gangrene. Ther Adv Urol. 2015;7(4):203-215. doi:10.1177/ 1756287215584740

25. Fukui K, Fujioka M, Ishiyama S. Sacral pressure ulcer-induced Fournier's gangrene extending to the retroperitoneum: a case report. Wounds. 2018;30(1):E5-E8.

26. Nigam V, Halim TA, Chhabra HS. Fournier's gangrene in a female with spinal cord injury: a case report. Spinal Cord. 2010;48(3):268-269. doi:10.1038/sc.2009.127

27. Perkins TA, Bieniek JM, Sumfest JM. Solitary Candida albicans infection causing Fournier gangrene and review of fungal etiologies. Rev Urol. 2014;16(2):95-98.
28. Yüksel ÖH, Ürkmez A, Akan S, Verit A. A case of Fournier's gangrene after inguinal hernia repair. Revista Internacional de Andrología. 2016;14(3):104-106. doi:10.1016/j. androl.2016.04.003

29. Chen Y, Wang X, Lin G, Xiao R. Successful treatment following early recognition of a case of Fournier's scrotal gangrene after a perianal abscess debridement: a case report. J Med Case Rep. 2018;12(1):193.

30. Mostaghim A, Dhanani M, Ingalls RR. Fournier's gangrene as an initial manifestation of acute promyelocytic leukemia: a case report and review of the literature. SAGE Open Med Case Rep. 2019;7:2050313X19834425. doi:10.1177/2050313X19834425

31. Katsanos KH, Ignatiadou E, Sarandi M, et al. Fournier's gangrene complicating ulcerative pancolitis. J Crohns Colitis. 2010;4 (2):203-206. doi:10.1016/j.crohns.2009.11.006

32. Dinc T, Kayilioglu SI, Sozen I, Yildiz BD, Coskun F. Fournier's gangrene as a postoperative complication of inguinal hernia repair. Case Rep Surg. 2014;2014:408217.

33. Tang L-M, Su Y-J, Lai Y-C. The evaluation of microbiology and prognosis of Fournier's gangrene in past five years. Springerplus. 2015;4(1):14. doi:10.1186/s40064-014-0783-8

34. Demir CY, Yuzkat N, Ozsular Y, Kocak OF, Soyalp C, Demirkiran H. Fournier gangrene: association of mortality with the complete blood count parameters. Plast Reconstr Surg. 2018;142(1):68e-75e. doi:10.1097/PRS.0000000000004516

35. Magdaleno-Tapial J, Valenzuela-Oñate $C$, Martínez-Doménech A, Sánchez-Carazo JL, Pérez-Ferriols A. Image gallery: Fournier gangrene in a patient with severe hidradenitis suppurativa. $\mathrm{Br}$ J Dermatol. 2019;181(3):e59. doi:10.1111/bjd.18052

36. Saijo S, Kuramoto Y, Yoshinari M, Tagami H. Extremely extended Fournier's gangrene. Dermatologica. 1990;181(3):228-232. doi: $10.1159 / 000247930$

37. Cocanour CS, Chang P, Huston JM, et al. Management and novel adjuncts of necrotizing soft tissue infections. Surg Infect (Larchmt). 2017;18(3):250-272. doi:10.1089/sur.2016.200

38. Bonne SL, Kadri SS. Evaluation and management of necrotizing soft tissue infections. Infect Dis Clin North Am. 2017;31 (3):497-511. doi:10.1016/j.idc.2017.05.011

39. Safioleas M, Stamatakos M, Mouzopoulos G, Diab A, Kontzoglou K, Papachristodoulou A. Fournier's gangrene: exists and it is still lethal. Int Urol Nephrol. 2006;38(3-4):653-657. doi:10.1007/s11255-0052946-6

40. Eke N. Fournier's gangrene: a review of 1726 cases. Br J Surg. 2000;87(6):718-728. doi:10.1046/j.1365-2168.2000.01497.x

41. Lin WT, Chao CM, Lin HL, Hung MC, Lai CC. Emergence of antibiotic-resistant bacteria in patients with Fournier gangrene. Surg Infect (Larchmt). 2015;16(2):165-168. doi:10.1089/ sur.2013.118

42. Anantha RV, Kasper KJ, Patterson KG, Zeppa JJ, Delport J, McCormick JK. Fournier's gangrene of the penis caused by Streptococcus dysgalactiae subspecies equisimilis: case report and incidence study in a tertiary-care hospital. BMC Infect Dis. 2013;13:381. doi:10.1186/1471-2334-13-381

43. Schmitz M, Roux X, Huttner B, Pugin J. Streptococcal toxic shock syndrome in the intensive care unit. Ann Intensive Care. 2018;8(1):88. doi:10.1186/s13613-018-0438-y

44. Grinev MV, Soroka IV, Grinev KM. [Fournier's gangrene-a model of necrotizing fasciitis (clinical and pathogenetic aspects)]. Urologiia. 2007;(6):69-73. Russian.

45. Misiakos EP, Bagias G, Patapis P, Sotiropoulos D, Kanavidis P, Machairas A. Current concepts in the management of necrotizing fasciitis. Front Surg. 2014;1:36. doi:10.3389/fsurg.2014.00036

46. Jaworski $\mathrm{R}$, Irga-Jaworska $\mathrm{N}$, Naumiuk $€$, Chojnicki $\mathrm{M}$, Haponiuk I. Fournier gangrene caused by Candida albicans in an infant after cardiac surgery. Mycopathologia. 2017;182(3-4):409-412. doi:10.1007/s11046-016-0086-4 
47. Crowell W, Roberts R, Tarry S. Fungal Fourniers gangrene in an immunocompromised patient. Urol Case Rep. 2015;4:1-3.

48. Durand CM, Alonso CD, Subhawong AP, et al. Rapidly progressive cutaneous Rhizopus microsporus infection presenting as Fournier's gangrene in a patient with acute myelogenous leukemia. Transpl Infect Dis. 2011;13(4):392-396. doi:10.1111/j.13993062.2011.00601.x

49. Tleyjeh IM, Routh J, Qutub MO, Lischer G, Liang KV, Baddour LM. Lactobacillus gasseri causing Fournier's gangrene. Scand J Infect Dis. 2004;36(6-7):501-503. doi:10.1080/ 00365540410015916

50. Jensen P, Zachariae C, Grønhøj Larsen F. Necrotizing soft tissue infection of the glans penis due to atypical Candida species complicated with Fournier's gangrene. Acta Derm Venereol. 2010;90(4):431-432. doi:10.2340/00015555-0847

51. Crowell W, Roberts R, Tarry S. Fungal Fourniers gangrene in an immunocompromised patient. Urol Case Rep. 2016;4:1-3. doi:10.1016/j.eucr.2015.09.009

52. Johnin K, Nakatoh M, Kadowaki T, Kushima M, Koizumi S, Okada Y. Fournier's gangrene caused by Candida species as the primary organism. Urology. 2000;56(1):153. doi:10.1016/S00904295(00)00527-6

53. Goh T, Goh LG, Ang CH, Wong CH. Early diagnosis of necrotizing fasciitis. $B r J$ Surg. 2014;101(1):e119-125. doi:10.1002/ bjs. 9371

54. Wong CH, Chang HC, Pasupathy S, Khin LW, Tan JL, Low CO. Necrotizing fasciitis: clinical presentation, microbiology, and determinants of mortality. J Bone Joint Surg Am. 2003;85 (8):1454-1460. doi:10.2106/00004623-200308000-00005

55. Parry N. Fournier gangrene. Clin Case Rep. 2015;3(3):198-199. doi: $10.1002 / \mathrm{ccr} 3.186$

56. Ferreira PC, Reis JC, Amarante JM, et al. Fournier's gangrene: a review of 43 reconstructive cases. Plast Reconstr Surg. 2007;119(1):175-184. doi:10.1097/01.prs.0000244925.80290.57

57. Talwar A, Puri N, Singh M. Fournier's Gangrene of the penis: a rare entity. J Cutan Aesthet Surg. 2010;3(1):41-44. doi:10.4103/ 0974-2077.63394

58. Ferretti M, Saji AA, Phillips J. Fournier's gangrene: a review and outcome comparison from 2009 to 2016. Adv Wound Care (New Rochelle). 2017;6(9):289-295. doi:10.1089/wound.2017.0730

59. Montrief T, Long B, Koyfman A, Auerbach J. Fournier gangrene: a review for emergency clinicians. J Emerg Med. 2019;57 (4):488-500. doi:10.1016/j.jemermed.2019.06.023

60. Castleberg E, Jenson N, Dinh VA. Diagnosis of necrotizing faciitis with bedside ultrasound: the STAFF exam. West J Emerg Med. 2014;15(1):111-113. doi:10.5811/westjem.2013.8.18303

61. Torremadé Barreda J, Millán Scheiding M, Suárez Fernández C, et al. Fournier gangrene. A retrospective study of 41 cases. Cirugía Española (English Edition). 2010;87(4):218-223. doi:10.1016/S2173-5077(10)70051-X

62. Rodríguez Alonso A, Pérez García MD, Núñez López A, et al. [Fournier's gangrene: anatomo-clinical features in adults and children. Therapy update].Actas Urol Esp.2000;24(4):294-306. doi:10.1016/S0210-4806(00)72452-1.Spanish.

63. Fernando SM, Tran A, Cheng W, et al. Necrotizing soft tissue infection: diagnostic accuracy of physical examination, imaging, and LRINEC score: a systematic review and meta-analysis. Ann Surg. 2019;269(1):58-65. doi:10.1097/SLA.0000000000002774

64. Doluoğlu ÖG, Karagöz MA, Kılınç MF, et al. Overview of different scoring systems in Fournier's gangrene and assessment of prognostic factors. Turk $J$ Urol. 2016;42(3):190-196. doi:10.5152/tud.2016.14194

65. Girgin R, Cinar O, Bulut E, Akduman B, Mungan NA. The role of the Platelet Mass Index (PMI) as a new prognostic factor in Fournier's gangrene. Afri $J$ Urol. 2018;24(3):226-232. doi:10.1016/j.afju.2018.06.002
66. Wong CH, Khin LW, Heng KS, Tan KC, Low CO. The LRINEC (Laboratory Risk Indicator for Necrotizing Fasciitis) score: a tool for distinguishing necrotizing fasciitis from other soft tissue infections. Crit Care Med. 2004;32(7):1535-1541. doi:10.1097/ 01.CCM.0000129486.35458.7D

67. Burner E, Henderson SO, Burke G, Nakashioya J, Hoffman JR. Inadequate sensitivity of laboratory risk indicator to rule out necrotizing fasciitis in the emergency department. West J Emerg Med. 2016;17(3):333-336. doi:10.5811/westjem.2016.2.29069

68. Swain RA, Hatcher JC, Azadian BS, Soni N, De Souza B. A five-year review of necrotising fasciitis in a tertiary referral unit. Ann R Coll Surg Engl. 2013;95(1):57-60. doi:10.1308/003588413 X13511609956093

69. Hodgins N, Damkat-Thomas L, Shamsian N, Yew P, Lewis H, Khan K. Analysis of the increasing prevalence of necrotising fasciitis referrals to a regional plastic surgery unit: a retrospective case series. J Plast Reconstr Aesthet Surg. 2015;68(3):304-311. doi:10.1016/j.bjps.2014.11.003

70. Wilson MP, Schneir AB. A case of necrotizing fasciitis with a LRINEC score of zero: clinical suspicion should trump scoring systems. J Emerg Med. 2013;44(5):928-931. doi:10.1016/j. jemermed.2012.09.039

71. Hsiao CT, Chang CP, Huang TY, Chen YC, Fann WC, Spratley J. Prospective validation of the Laboratory Risk Indicator for Necrotizing Fasciitis (LRINEC) score for necrotizing fasciitis of the extremities. PLoS One. 2020;15(1):e0227748. doi:10.1371/ journal.pone. 0227748

72. Kabay S, Yucel M, Yaylak F, et al. The clinical features of Fournier's gangrene and the predictivity of the Fournier's gangrene severity index on the outcomes. Int Urol Nephrol. 2008;40 (4):997-1004. doi:10.1007/s11255-008-9401-4

73. Bozkurt O, Sen V, Demir O, Esen A. Evaluation of the utility of different scoring systems (FGSI, LRINEC and NLR) in the management of Fournier's gangrene. Int Urol Nephrol. 2015;47 (2):243-248. doi:10.1007/s11255-014-0897-5

74. Forget P, Khalifa C, Defour J-P, Latinne D, Van Pel M-C, De Kock M. What is the normal value of the neutrophil-tolymphocyte ratio? BMC Res Notes. 2017;10(1):12. doi:10.1186/ s13104-016-2335-5

75. Yim SU, Kim SW, Ahn JH, et al. Neutrophil to lymphocyte and platelet to lymphocyte ratios are more effective than the Fournier's gangrene severity index for predicting poor prognosis in Fournier's gangrene. Surg Infect (Larchmt). 2016;17 (2):217-223. doi:10.1089/sur.2015.126

76. Kahramanca S, Kaya O, Özgehan G, et al. Are neutrophillymphocyte ratio and platelet-lymphocyte ratio as effective as Fournier's gangrene severity index for predicting the number of debridements in Fournier's gangrene? Ulus Travma Acil Cerrahi Derg. 2014;20(2):107-112. doi:10.5505/tjtes.2014.62829

77. Selvi I, Aykac A, Baran O, Burlukkara S, Ozok U, Sunay MM. A different perspective for morbidity related to Fournier's gangrene: which scoring system is more reliable to predict requirement of skin graft and flaps in survivors of Fournier's gangrene? Int Urol Nephrol. 2019;51(8):1303-1311. doi:10.1007/s11255019-02188-0

78. Yíldírím A, Anuk T, Çı̆̆şar G. Clinical value of the monocyte-tolymphocyte ratio for determining number of debridements in treatment of Fournier's gangrene. Turk $J$ Colorect Dis. 2017;27:43.

79. Ash L, Hale J. CT findings of perforated rectal carcinoma presenting as Fournier's gangrene in the emergency department. Emerg Radiol. 2005;11(5):295-297. doi:10.1007/s10140-0050417-0

80. Anaya DA, Dellinger EP, Dellinger EP. Necrotizing soft-tissue infection: diagnosis and management. Clin Infect Dis. 2007;44 (5):705-710. doi:10.1086/511638 
81. Wysoki MG, Santora TA, Shah RM, Friedman AC. Necrotizing fasciitis: CT characteristics. Radiology. 1997;203(3):859-863. doi:10.1148/radiology.203.3.9169717

82. Levenson RB, Singh AK, Novelline RA. Fournier gangrene: role of imaging. Radiographics. 2008;28(2):519-528. doi:10.1148/ rg. 282075048

83. Rajan DK, Scharer KA. Radiology of Fournier's gangrene. AJR Am J Roentgenol. 1998;170(1):163-168. doi:10.2214/ ajr.170.1.9423625

84. Piedra T, Ruíz E, González FJ, Arnaiz J, Lastra P, López-Rasines G. Fournier's gangrene: a radiologic emergency. Abdom Imaging. 2006;31(4):500-502. doi:10.1007/s00261-006-9035-x

85. Yen ZS, Wang HP, Ma HM, Chen SC, Chen WJ. Ultrasonographic screening of clinically-suspected necrotizing fasciitis. Acad Emerg Med. 2002;9(12):1448-1451. doi:10.1197/ aemj.9.12.1448

86. Di Serafino M, Gullotto C, Gregorini C, Nocentini C. A clinical case of Fournier's gangrene: imaging ultrasound. J Ultrasound. 2014;17(4):303-306. doi:10.1007/s40477-014-0106-5

87. Stevens DL, Bisno AL, Chambers HF, et al. Practice guidelines for the diagnosis and management of skin and soft tissue infections: 2014 update by the Infectious Diseases Society of America. Clin Infect Dis. 2014;59(2):e10-52.

88. Morgan MS. Diagnosis and management of necrotising fasciitis: a multiparametric approach. J Hosp Infect. 2010;75(4):249-257. doi:10.1016/j.jhin.2010.01.028

89. Saifee NH, Evans HL, Magaret AS, et al. Outcomes in necrotizing soft tissue infections treated with therapeutic plasma exchange. Transfusion. 2017;57(6):1407-1413. doi:10.1111/ trf. 14067

90. Benjelloun El B, Souiki T, Yakla N, et al. Fournier's gangrene: our experience with 50 patients and analysis of factors affecting mortality. World J Emerg Surg. 2013;8(1):13. doi:10.1186/17497922-8-13

91. Semler MW, Self WH, Wanderer JP, et al. Balanced crystalloids versus saline in critically ill adults. $N$ Engl J Med. 2018;378 (9):829-839. doi:10.1056/NEJMoa1711584
92. Rhodes A, Evans LE, Alhazzani W, et al. Surviving sepsis campaign: international guidelines for management of sepsis and septic shock: 2016. Intensive Care Med. 2017;43(3):304-377.

93. Bentzer P, Griesdale DE, Boyd J, MacLean K, Sirounis D, Ayas NT. Will this hemodynamically unstable patient respond to a bolus of intravenous fluids? JAMA. 2016;316(12):1298-1309. doi:10.1001/jama.2016.12310

94. Monnet X, Marik P, Teboul JL. Passive leg raising for predicting fluid responsiveness: a systematic review and meta-analysis. Intensive Care Med. 2016;42(12):1935-1947. doi:10.1007/ s00134-015-4134-1

95. Rosa I, Guerreiro F. Hyperbaric oxygen therapy for the treatment of Fournier's gangrene: a review of 34 cases. Acta Med Port. 2015;28(5):619-623. doi:10.20344/amp.6300

96. Mindrup SR, Kealey GP, Fallon B. Hyperbaric oxygen for the treatment of Fournier's gangrene. $J$ Urol. 2005;173 (6):1975-1977. doi:10.1097/01.ju.0000158129.56571.05

97. Norrby-Teglund A, Muller MP, McGeer A, et al. Successful management of severe group A streptococcal soft tissue infections using an aggressive medical regimen including intravenous polyspecific immunoglobulin together with a conservative surgical approach. Scand J Infect Dis. 2005;37(3):166-172. doi:10.1080/00365540410020866

98. Abdrabou A. Fournier gangrene. Radiopedia. Available from: https://radiopaedia.org/cases/fournier-gangrene-5?lang=us. Accessed October 01, 2020.

99. O’Donnell C. Fournier gangrene - spontaneous perforation of rectal cancer. Radiopedia. Available from: https://radiopaedia. org/cases/fournier-gangrene-spontaneous-perforation-of-rectalcancer?lang=us. Accessed October 01, 2020.

100. Jha P. Fournier gangrene. Radiopedia. Available from: https:// radiopaedia.org/cases/fournier-gangrene-1?lang=us. Accessed October 01, 2020.

\section{Publish your work in this journal}

The Open Access Emergency Medicine is an international, peerreviewed, open access journal publishing original research, reports, editorials, reviews and commentaries on all aspects of emergency medicine. The manuscript management system is completely online and includes a very quick and fair peer-review system, which is all easy to use. Visit http://www.dovepress.com/testimonials.php to read real quotes from published authors. 